\title{
Mediterranean Diet and Motivation in Sport: A Comparative Study Between University Students from Spain and Romania
}

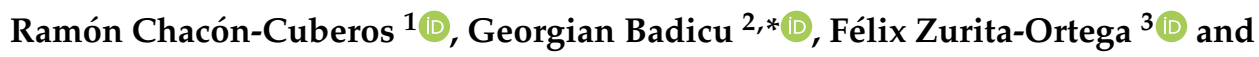 \\ Manuel Castro-Sánchez ${ }^{3}$ iD \\ 1 Department of Education. University of Almería, 04120 Almería, Spain; rchacon@ual.es \\ 2 Department of Physical Education and Special Motility, Faculty of Physical Education and Mountain Sports, \\ Transilvania University of Brasov, 500068 Brasov, Romania \\ 3 Department of Didactics of Musical, Plastic and Corporal Expression, University of Granada, 18071 Granada, \\ Spain; felixzo@ugr.es (F.Z.-O.); manuelcs@ugr.es (M.C.-S.) \\ * Correspondence: georgian.badicu@unitbv.ro; Tel.: +40-769-219-271
}

Received: 11 November 2018; Accepted: 20 December 2018; Published: 22 December 2018

\begin{abstract}
Background: The Mediterranean Diet (MD) is one of the healthiest dietary models worldwide, being an essential mean of preventing pathologies along with the practice of physical activity. Through a comparative study carried out across different countries, it has been demonstrated how this type of habits vary depending on the geographical context. The aim of this research was to evaluate the adherence to MD and its relationships with motivational climate in sport on a sample of university students from Spain and Romania; Methods: A cross-sectional study was conducted on a sample of university students [specialization: Physical Education $(n=605 ; 20.71 \pm 2.42$ years old)], using as main instruments the Mediterranean Diet Quality Index (KIDMED) for students and adolescents and the Perceived Motivational Climate in Sport Questionnaire-2 (PMCSQ-2); Results: It was shown that students from Spain had a high adherence to the MD $(6.65 \pm 2.63 \mathrm{vs} .5 .06 \pm 1.31)$. Spanish university students got higher scores in task-oriented motivational climate (4.03 $\pm 0.62 \mathrm{vs}$. $3.11 \pm 0.55)$ while ego-oriented climate was higher in university students from Romania ( $3.24 \pm 0.54$ vs. $2.07 \pm 0.75)$. Finally, it was observed that the task-oriented motivational climate was related to a lower adherence to MD in Spanish students ( $4.49 \pm 0.37$ vs. $3.98 \pm 0.62)$. In contrast, in Romanian youth, a medium adherence to the MD was associated with higher scores for the ego-oriented motivational climate $(3.27 \pm 0.53$ vs. $3.00 \pm 0.54)$; Conclusions: As main conclusions, it was shown that the students from Spain had a high adherence to the MD. In addition, it has been demonstrated that ego-oriented climates are linked to a better adherence to MD, especially due to the importance of following a proper diet in sport contexts, as demonstrated by young Romanians.
\end{abstract}

Keywords: Mediterranean diet; motivational climate; sports; university students

\section{Introduction}

Being overweight (body mass index of 25 or higher) and its associated pathologies have become a problem in society nowadays, which is why the importance of following a healthy diet and lifestyle has gained much prominence [1-3]. The diet models that exist in the world are numerous and varied, each one with particular characteristics [3]. Dietary habits represent important elements for the quality of life and especially for young people [4]. Utilizing different dietary models, several authors state the importance of making a change in people's eating habits in European countries in order to reduce the risk of different types of diseases $[5,6]$. The Mediterranean Diet (MD) is one of the most studied model 
as it is associated with different benefits, such as a better health due to a high consumption of natural antioxidants and a low intake of fats. In addition, MD improves the cognitive function, decreases the risk of diabetes, bone diseases and overweight [6-8].

This dietary model is characterized by typical foods of the Mediterranean basin such as legumes, fruits, cereals and olive oil, with a moderate consumption of eggs, fish and dairy products $[4,9,10]$. It has been shown that people with a good adherence to MD have a high quality of life and life expectancy [11], as this diet has several benefits on public health [12], social relationships [13], sport performance [14] and emotional factors [15,16]. Furthermore, the influence of MD on young people living around the Mediterranean Sea has been studied in countries such as Cyprus, Italy, Creece, Turkey, Spain, Lebanon and Croatia [4,13,15-21]. Additionally, this dietary model has been analysed in various cultural and socio-economic contexts $[10,22,23]$.

Several studies demonstrate the benefits of a high adherence to the MD [24-27]. This dietary model helps to improve body composition, favouring the decrease in the percentage of fat mass thanks to its low consumption in hypercaloric foods and foods rich in saturated fats [25]. In addition, MD helps to prevent diabetes, since this model is based on the consumption of foods with a low glycaemic index, such as fruits, vegetables and cereals [26]. Another benefit lies in the Non-alcoholic fatty liver disease, since Trovato et al. [27] demonstrated in an intervention study how a better adherence to MD improved the progress of this pathology due to a greater caloric restriction that generates temporary changes in the liver such as a better sensitivity to hepatic insulin or a lower content of triglycerides. Finally, $\mathrm{O}^{\prime} \mathrm{Neil}$ et al. [28] highlight some of the benefits of MD at cognitive level, such as an improvement of states of depression and anxiety or a better academic performance.

Regular and adequate Physical Activity (PA) in addition to following a healthy diet is essential for the improvement of health. Several studies show how performing a minimum of 90 minutes of moderate PA weekly helps to improve health, body composition or bone mineral density, as well as pulmonary and cardiovascular functions [29,30]. In addition, regular PA decreases anxiety and stress and improves self-concept, well-being and self-esteem [31,32]. For these reasons, promoting this type of habits is essential among university students, since many habits developed in early adulthood are reinforced later in life [21]. In this sense, it is essential to study the motivational aspects that allow to create adherence to the practice of PA, which will be linked to other healthy habits such as adopting a healthy diet.

The Achievement Goals Theory has been one of the most used explanatory models in order to explain the motivational processes involved in sports practice $[33,34]$. This theory establishes that people set objectives in sports, which will be related to the person's perception of their own abilities. Therefore, the goals pursued by an individual can be linked to motivational climates oriented toward the task or the ego $[33,35]$. In the first case, the task-oriented climate will be linked to team work, to higher levels of effort to learn and the assignment of an important role in the task [36]. The ego-oriented climate is related to people whose goals depend on the social recognition that they will achieve through competition within the sport context [36,37]. Considering the premises exposed by Ryan et al. [38] in the Self-Determination Theory, the task-oriented climate will be associated with intrinsic motivations, while the ego climate will be related to extrinsic motivations [39]. In this regard, it has been shown that certain types of motivations can be linked to healthy or non-healthy behaviours [40-42].

Studies such as those carried out by Chacón et al. [43] or Erturan-Ilker et al. [44] analyse the relationship between motivation in sport and different healthy habits, such as the consumption of harmful substances, the practice of PA or adherence to MD. Although the adherence to MD has been studied in association with physical and healthy lifestyles, a few studies connect it with motivation in sport, as well as with cultural-geography factors. Thus, it is interesting to study these variables in order to promote MD in non-Mediterranean populations [19,45,46]. In view of the above, the present study will provide novel data about the importance of the MD in relation to sociodemographic and motivational parameters in a sample of university students of Physical Education from two countries: Spain and Romania. 
The present study establishes two aims: (a) to assess the level of adherence to MD in a sample of university students from Spain and Romania; (b) to analyse the relationship between adherence to MD and motivational climate in sport depending on the country (Spain or Romania); (c) to contrast a structural equation model about the relationship between MD and motivational climate using multi-group analysis.

\section{Materials and Methods}

\subsection{Subjects and Design}

This non-experimental, cross-sectional and descriptive research was conducted on a sample of 651 university students from Spain and Romania, enrolled in the Physical Education degrees, aged between 18 and 24 years old $(20.71 \pm 2.42$ years). The respondents participated voluntarily after receiving a detailed explanation of the objectives and nature of the study. Written informed consent was provided. We excluded from the analysis 46 participants that did not complete the inclusion criteria correctly (i.e., incomplete questionnaires, did not hand informed consent forms), thus the final sample was comprised of 605 subjects (368 males and 237 females): Romania $(n=178)$ and Spain $(n=427)$. The students from Romania were enrolled in the Transylvania University of Brasov, while the Spanish students were enrolled in the University of Granada. Finally, an assumed sampling error of 0.05 was taken into account, considering a random sampling by natural groups [47].

\subsection{Instruments}

Test of Adherence to Mediterranean Diet (KIDMED) [48]. This scale comprises 16 items with an affirmative or negative response; for example: "You eat fruit every day", which are related to patterns associated with the MD. Twelve of these items have positive connotations $(+1)$ while the other four have negative values $(-1)$. The final score ranges from -4 to +12 . This instrument has a reliability of $\alpha=0.86$.

Perceived Motivational Climate in Sport Questionnaire (PMCSQ-2, [49,50]). This instrument is composed by 33 items which are scored by a five-point Likert-scale, ranging from 1 to 5 (Strongly Disagree-Strongly agree). The scale comprised two factors, higher-order dimensions, each containing three indicators. For task-oriented climate the indicators were: effort/improvement, cooperative learning and important role. For ego-oriented climate the indicators were: unequal recognition, member rivalry and punishment for mistakes. The internal consistency for this questionnaire was $\alpha=0.85$ for task-climate and $\alpha=0.82$ for ego-climate.

\subsection{Procedure}

First, we proceeded to request the approval of the study by the Ethics Committee of the University of Granada, which was granted with code "641/CEIH/2018". Subsequently, the collaboration of educational centres was requested through an informative letter elaborated by the Area of Corporal Expression of the University of Granada. In addition, the informed consent of the respondents was requested through a document in which the nature of the study was detailed.

The data was collected during regular classes in the different university campus. Different research assistants were present in the data collection in order to ensure that questionnaires were properly completed, to provide guidance on the completion of scales and to answer questions. Furthermore, participants receive any incentives.

\subsection{Data Analysis}

Statistical analysis was conducted using the software IBM SPSS $® 22.0$ (IBM Corp., Armonk, NY, USA). Frequencies and medians were used for basic descriptors, whereas the association between the variables detailed were analysed using T-test and ANOVA-test. In addition, the Kolmogorov-Smirnov's test was used in order to check the normality of data, as well as the Lillieforts' 
correction. Levene's test was employed in order to check homoscedasticity. Finally, Cronbach's Alpha coefficient was used to analyse the internal reliability of the instruments used, establishing the Reliability Index at 95\%. In addition, AMOS version 23.0 (IBM Corp., Armonk, NY, USA) is used for the structural equation analysis.

The Structural Equation Model (SEM) is composed by seven observed variables and two latent variables (Figure 1). Task-involved climate (TC) and ego-involved climate (EC) represent the exogenous variables, which is inferred by three indicators. Effort/Improvement (EI), Cooperative learning (CL) and Important Role (RI) are the indicators for task-oriented climate while Unequal Recognition (UR), Member Rivalry (MR) and Punishment for Mistakes (PM) are the indicators for ego-oriented climate. On the contrary, the Mediterranean diet (MD) was the observed endogenous variable. The bi-directional arrow (covariance) relates exogenous variables, while the unidirectional arrows are lines of influence between the latent and observable indicators and are interpreted as multivariate regression coefficients. In addition, error prediction terms are associated with endogenous variables. The method of maximum likelihood (ML) was used to estimate relationships between variables. We chose this method because it is consistent, unbiased and invariant to types of scale given variables with a normal distribution.

Model fit was tested using several indices. Chi-squared analysis followed when non-significant p-values indicated good model fit. Normalized Fit Index (NFI), Comparative Fit Index (CFI) and Increase Fit Index (IFI) values higher than 0.90 indicate acceptable model fit while values higher than 0.95 indicate excellent model fit. Root Mean Square Error of Approximation (RMSEA) values below 0.08 indicate acceptable model fit while values below 0.05 indicate excellent model fit.

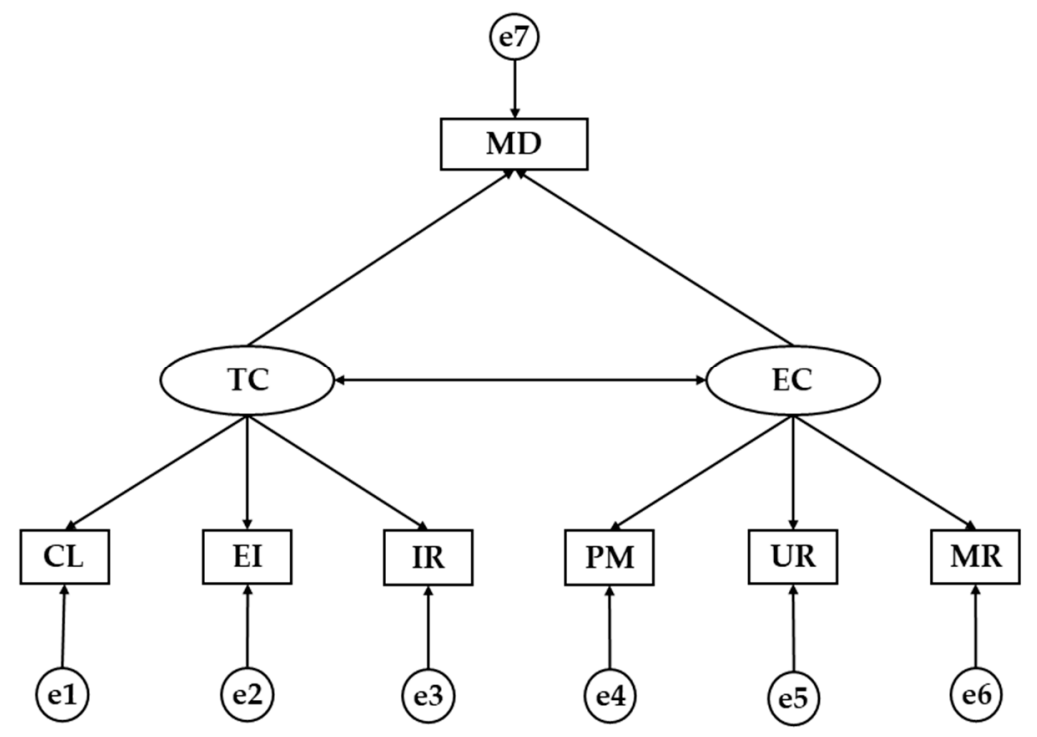

Figure 1. Theoretical model. TC, Task Climate; EC, Ego Climate; CL, Cooperative Learning; EI, Effort/Improvement; IR, Important Role; PM, Punishment for Mistakes; UR, Unequal Recognition; MR, Member Rivalry; MD, Mediterranean Diet.

\section{Results}

Table 1 shows the average scores obtained in each item of the test on adherence to the MD, according to the country of origin of the university students enrolled in Physical Education degrees. In this way, statistically significant differences $(p<0.05)$ were found in fruit and daily fruit juice consumption $(0.27 \pm 0.44$ vs. $0.77 \pm 0.41)$ and in the intake of a daily second fruit $(0.78 \pm 0.41 \mathrm{vs}$. $0.42 \pm 0.49$ ), obtaining a higher score for Spanish students in the first case and in Romanians in the second. Moreover, Spanish students obtained higher scores for fish consumption (0.42 $\pm 0.49 \mathrm{vs}$. $0.67 \pm 0.46)$, pulses more than once a week $(0.63 \pm 048$ vs. $0.71 \pm 0.45)$, cereal consumption $(0.71 \pm 0.45$ vs. $0.86 \pm 0.34)$ and dairy consumption $(0.26 \pm 0.44$ vs. $0.81 \pm 0.39)$, showing statistically significant 
differences in all the relationships. In addition, students from Romania obtained higher mean values than Spaniards in vegetable consumption ( $0.88 \pm 0.33$ vs. $0.33 \pm 0.47)$, pasta and rice consumption $(0.76 \pm 0.42$ vs. $0.42 \pm 0.49)$ and nut use $(0.93 \pm 0.25$ vs. $0.50 \pm 0.50)$. Nevertheless, Romanian students got the highest scores on negative items, showing a higher absolute mean value for fast food $(-0.56 \pm 0.49$ vs. $-0.34 \pm 0.47)$, jumping breakfast $(-0.46 \pm 0.49)$ vs. $-0.31 \pm 0.46)$, processed food intake $(-0.89 \pm 0.31$ vs. $-0.12 \pm 0.32)$ and sweets intakes $(-0.79 \pm 0.40$ vs. $-0.17 \pm 0.37)$. Finally, Spanish students obtained a higher average value in the total score for adherence to the MD (5.06 \pm 1.31 vs. $6.65 \pm 2.63)$.

Table 1. Dietary patterns depending on country.

\begin{tabular}{|c|c|c|c|c|c|c|}
\hline \multirow{2}{*}{ Items of Adherence to MD } & \multirow[b]{2}{*}{ Country } & \multirow[b]{2}{*}{ A } & \multirow[b]{2}{*}{ SD } & \multicolumn{2}{|c|}{ Levene's Test } & \multirow{2}{*}{$\begin{array}{l}\text { T-Test } \\
\text { Sig. }\end{array}$} \\
\hline & & & & F & Sig. & \\
\hline \multirow{2}{*}{ I1. To eat a fruit or fruit juice every day } & Romania & 0.27 & 0.44 & \multirow{2}{*}{4.65} & \multirow{2}{*}{0.031} & \multirow{2}{*}{$* * *$} \\
\hline & Spain & 0.77 & 0.41 & & & \\
\hline \multirow{2}{*}{ I2. To have a second fruit every day } & Romania & 0.78 & 0.41 & \multirow{2}{*}{119.95} & \multirow{2}{*}{0.000} & \multirow{2}{*}{$* * *$} \\
\hline & Spain & 0.42 & 0.49 & & & \\
\hline \multirow{2}{*}{$\begin{array}{l}\text { I3. To eat fresh or cooked vegetables } \\
\text { regularly once a day }\end{array}$} & Romania & 0.55 & 0.49 & \multirow[b]{2}{*}{6.91} & \multirow{2}{*}{0.009} & \multirow[b]{2}{*}{0.109} \\
\hline & Spain & 0.62 & 0.48 & & & \\
\hline \multirow{2}{*}{$\begin{array}{l}\text { I4. To consume fresh or cooked vegetables } \\
\text { more than once a day }\end{array}$} & Romania & 0.88 & 0.33 & \multirow{2}{*}{181.53} & \multirow{2}{*}{0.000} & \multirow{2}{*}{$* * *$} \\
\hline & Spain & 0.33 & 0.47 & & & \\
\hline \multirow{2}{*}{$\begin{array}{l}\text { I5. Regular fish consumption (at least } \\
2-3 \text { /week) }\end{array}$} & Romania & 0.42 & 0.49 & \multirow{2}{*}{14.27} & \multirow{2}{*}{0.000} & \multirow{2}{*}{$* * *$} \\
\hline & Spain & 0.67 & 0.46 & & & \\
\hline \multirow{2}{*}{$\begin{array}{l}\text { I6. To go }>1 \text { / week to a fast food } \\
\text { restaurant (hamburger) }\end{array}$} & Romania & -0.56 & 0.49 & \multirow{2}{*}{14.83} & 0000 & $* * *$ \\
\hline & Spain & -0.34 & 0.47 & & 0.000 & \\
\hline I7 P11ses >1/yrook & Romania & 0.63 & 0.48 & & & \\
\hline 17. Pulses > 1/ week & Spain & 0.71 & 0.45 & 13.77 & 0.000 & * \\
\hline I8. To eat pasta or rice almost every day ( 5 & Romania & 0.76 & 0.42 & 10634 & 0000 & $* * *$ \\
\hline or more per week) & Spain & 0.42 & 0.49 & 106.34 & 0.000 & (n) \\
\hline I9. To have cereals or grains (bread, etc.) & Romania & 0.71 & 0.45 & & & \\
\hline for breakfast & Spain & 0.86 & 0.34 & 66.35 & 0.000 & $* * * *$ \\
\hline I10. To consume nuts regularly (at least & Romania & 0.93 & 0.25 & & & \\
\hline $2-3 /$ week) & Spain & 0.50 & 0.50 & 1266.61 & 0.000 & $* * * *$ \\
\hline & Romania & 0.99 & 0.07 & & & \\
\hline I11. To use olive oil at home & Spain & 0.99 & 0.09 & 0.86 & 0.353 & 0.643 \\
\hline & Romania & -0.46 & 0.49 & & & \\
\hline 112. No breakfast & Spain & -0.31 & 0.46 & 24.63 & 0.000 & th \\
\hline I13. To have a dairy product for breakfast & Romania & 0.26 & 0.44 & & & \\
\hline (yoghurt, milk, etc.) & Spain & 0.81 & 0.39 & 15.15 & 0.000 & $* * *$ \\
\hline I14. To eat commercially baked goods or & Romania & -0.89 & 0.31 & 0.42 & 0.513 & $* * *$ \\
\hline pastries for breakfast & Spain & -0.12 & 0.32 & 0.42 & & \\
\hline I15. To consume two yoghurts and/or & Romania & 0.56 & 0.49 & 242 & 0120 & 0070 \\
\hline some cheese ( $40 \mathrm{~g}$ ) daily & Spain & 0.48 & 0.50 & 2.42 & 0.120 & \\
\hline I16. To have sweets and candy several & Romania & -0.79 & 0.40 & 564 & 0018 & $* * *$ \\
\hline times every day & Spain & -0.17 & 0.37 & 5.64 & 0.018 & \\
\hline Clohal sore in adherence & Rumanía & 5.06 & 1.31 & 10188 & 0000 & $* * *$ \\
\hline Glopal score in adnerence to IVD & España & 6.65 & 2.63 & 101.80 & 0.000 & \\
\hline
\end{tabular}

* Statistically significant differences at level $p<0.05 ; * *$ Statistically significant differences at level $p<0.01$; *** Statistically significant differences at level $p<0.001$. A, Average; SD, Standard Deviation. MD, Mediterranean Diet.

Scores obtained for motivational climate according to the country are shown in Table 2, showing statistically significant differences at level $p<0.001$ for all relationships. University students from Spain got higher values for Task-oriented Climate ( $3.11 \pm 0.55$ vs. $4.03 \pm 0.62)$ and its categories: Cooperative Learning ( $2.93 \pm 0.75$ vs. $4.06 \pm 0.72)$, Effort/Improvement ( $3.34 \pm 0.53$ vs. $3.97 \pm 0.63$ ) and Important Role ( $2.87 \pm 0.86$ vs. $4.10 \pm 0.73)$. Furthermore, students from Romania showed the 
highest scores in Ego-oriented Climate (3.24 \pm 0.24 vs. $2.07 \pm 0.75)$ and its categories: Punishment for Mistakes (3.24 \pm 0.61 vs. $1.93 \pm 0.79)$, Unequal Recognition (3.17 \pm 0.70 vs. $1.98 \pm 0.89)$ and Member Rivalry (3.39 \pm 0.80 vs. $2.56 \pm 0.95)$.

Table 2. Motivational climate in sport depending on country.

\begin{tabular}{|c|c|c|c|c|c|c|}
\hline \multirow{2}{*}{$\begin{array}{c}\text { Dimensions of } \\
\text { Motivational Climate }\end{array}$} & \multirow{2}{*}{ Country } & \multirow{2}{*}{ A } & \multirow{2}{*}{ SD } & \multicolumn{2}{|c|}{ Levene's Test } & \multirow{2}{*}{$\begin{array}{l}\text { T-Test } \\
\text { Sig. }\end{array}$} \\
\hline & & & & F & Sig. & \\
\hline \multirow{2}{*}{$\mathrm{TC}$} & Romania & 3.11 & 0.55 & \multirow{2}{*}{2.720} & \multirow{2}{*}{0.100} & \multirow{2}{*}{$* * *$} \\
\hline & Spain & 4.03 & 0.62 & & & \\
\hline \multirow{2}{*}{$\mathrm{CL}$} & Romania & 2.93 & 0.75 & \multirow{2}{*}{4.363} & \multirow{2}{*}{0.037} & \multirow{2}{*}{$* * *$} \\
\hline & Spain & 4.06 & 0.72 & & & \\
\hline \multirow{2}{*}{ EI } & Romania & 3.34 & 0.53 & \multirow{2}{*}{4.477} & \multirow{2}{*}{0.035} & \multirow{2}{*}{$* * *$} \\
\hline & Spain & 3.97 & 0.63 & & & \\
\hline \multirow{2}{*}{ IR } & Romania & 2.87 & 0.86 & \multirow{2}{*}{8.223} & \multirow{2}{*}{0.004} & \multirow{2}{*}{$* * *$} \\
\hline & Spain & 4.10 & 0.73 & & & \\
\hline \multirow{2}{*}{$\mathrm{EC}$} & Romania & 3.24 & 0.54 & \multirow{2}{*}{18.175} & \multirow{2}{*}{0.000} & \multirow{2}{*}{$* * *$} \\
\hline & Spain & 2.07 & 0.75 & & & \\
\hline \multirow[b]{2}{*}{ PM } & Romania & 3.24 & 0.61 & \multirow[b]{2}{*}{14.471} & \multirow[b]{2}{*}{0.000} & \multirow{2}{*}{$* * *$} \\
\hline & Spain & 1.93 & 0.79 & & & \\
\hline \multirow{2}{*}{ UR } & Romania & 3.17 & 0.70 & \multirow{2}{*}{6.259} & \multirow{2}{*}{0.013} & \multirow{2}{*}{$* * *$} \\
\hline & Spain & 1.98 & 0.89 & & & \\
\hline \multirow{2}{*}{ MR } & Romania & 3.39 & 0.80 & \multirow{2}{*}{14.872} & \multirow{2}{*}{0.000} & \\
\hline & Spain & 2.56 & 0.95 & & & $* * * *$ \\
\hline
\end{tabular}

*** Statistically significant differences at level $p<0.001$. TC, Task-oriented Climate; CL, Cooperative Learning; EI, Effort/Improvement; IR, Important Role; EC, Ego-oriented Climate; PM, Punishment for Mistakes; UR, Unequal Recognition; MR, Member Rivalry. A, Average; SD, Standard Deviation.

Table 3 shows the relationships between adherence to MD and motivational climate in the university students of both countries. Romanian students revealed statistical differences at level $p<0.05$ for Ego-oriented Climate ( $3.27 \pm 0.53$ vs. $3.00 \pm 0.54)$ and punishment for Mistakes (3.28 \pm 0.61 vs. $2.96 \pm 0.50)$ showing higher scores for medium adherence to MD than for higher adherence. In addition, statically significant differences at level $p<0.01$ were found for Member Rivalry with a high average for medium adherence $(3.45 \pm 0.76$ vs. $2.93 \pm 0.96$. Moreover, Spanish students showed significant differences at level $p<0.05$ with higher values for low adherence to MD than medium adherence in Task-oriented Climate ( $4.49 \pm 0.37$ vs. $3.98 \pm 0.62)$, Cooperative Learning (4.60 \pm 0.37 vs. $4.01 \pm 0.72)$ and Effort/Improvement ( $4.37 \pm 0.53$ vs. $3.90 \pm 0.65$ ). 
Table 3. Adherence to MD according to motivational climate and country.

\begin{tabular}{|c|c|c|c|c|c|c|c|}
\hline \multirow{2}{*}{\multicolumn{2}{|c|}{$\begin{array}{c}\text { Level of Adherence to MD } \\
\text { According to Motivational Climate }\end{array}$}} & \multicolumn{3}{|c|}{ Romania } & \multicolumn{3}{|c|}{ Spain } \\
\hline & & $\mathbf{A}$ & DT & $\mathbf{P}$ & $\mathbf{A}$ & DT & $\mathbf{P}$ \\
\hline \multirow{3}{*}{ TC } & Low adherence & - & - & \multirow{3}{*}{0.263} & 4.49 & 0.37 & \multirow{3}{*}{ * } \\
\hline & Medium adherence & 3.12 & 0.54 & & 3.98 & 0.62 & \\
\hline & High adherence & 2.98 & 0.56 & & 4.06 & 0.62 & \\
\hline \multirow{3}{*}{$\mathrm{CL}$} & Low adherence & - & - & \multirow{3}{*}{0.677} & 4.60 & 0.37 & \multirow{3}{*}{ * } \\
\hline & Medium adherence & 2.94 & 0.73 & & 4.01 & 0.72 & \\
\hline & High adherence & 2.87 & 0.90 & & 4.10 & 0.71 & \\
\hline \multirow{3}{*}{ EI } & Low adherence & - & - & \multirow{3}{*}{0.313} & 4.37 & 0.53 & \multirow{3}{*}{ * } \\
\hline & Medium adherence & 3.35 & 0.52 & & 3.90 & 0.65 & \\
\hline & High adherence & 3.23 & 0.61 & & 4.02 & 0.60 & \\
\hline \multirow{3}{*}{ IR } & Low adherence & - & - & \multirow{3}{*}{0.253} & 4.60 & 0.37 & \multirow{3}{*}{0.305} \\
\hline & Medium adherence & 2.90 & 0.88 & & 4.10 & 0.71 & \\
\hline & High adherence & 2.68 & 0.67 & & 4.08 & 0.76 & \\
\hline \multirow{3}{*}{$\mathrm{EC}$} & Low adherence & - & - & \multirow{3}{*}{ * } & 1.87 & 0.81 & \multirow{3}{*}{0.491} \\
\hline & Medium adherence & 3.27 & 0.53 & & 2.04 & 0.71 & \\
\hline & High adherence & 3.00 & 0.54 & & 2.11 & 0.78 & \\
\hline \multirow{3}{*}{ PM } & Low adherence & - & - & \multirow{3}{*}{ * } & 1.66 & 0.39 & \multirow{3}{*}{0.391} \\
\hline & Medium adherence & 3.28 & 0.61 & & 1.89 & 0.75 & \\
\hline & High adherence & 2.96 & 0.50 & & 1.98 & 0.82 & \\
\hline \multirow{3}{*}{ UR } & Low adherence & - & - & \multirow{3}{*}{0.400} & 1.85 & 1.16 & \multirow{3}{*}{0.885} \\
\hline & Medium adherence & 3.19 & 0.71 & & 1.97 & 0.86 & \\
\hline & High adherence & 3.05 & 0.70 & & 2.00 & 0.92 & \\
\hline \multirow{3}{*}{ MR } & Low adherence & - & - & \multirow{3}{*}{$* *$} & 2.33 & 1.17 & \multirow{3}{*}{0.225} \\
\hline & Medium adherence & 3.45 & 0.76 & & 2.49 & 0.90 & \\
\hline & High adherence & 2.93 & 0.96 & & 2.64 & 0.99 & \\
\hline
\end{tabular}

* Statistically significant differences at level $p<0.05$; $* *$ Statistically significant differences at level $p<0.01$. TC, Task-oriented Climate; CL, Cooperative Learning; EI, Effort/Improvement; IR, Important Role; EC, Ego-oriented Climate; PM, Punishment for Mistakes; UR, Unequal Recognition; MR, Member Rivalry. MD, Mediterranean Diet. A, Average; SD, Standard Deviation.

Finally, a structural equation model is developed in order to compare the relationships between all the analysed factors according to the country (Figures 2 and 3). Almost all fit indices of model suggested good fit. A significant chi-square value was obtained $\left(\chi^{2}=126.85 ; \mathrm{df}=5.28 ; p<0.001\right)$. Nevertheless, as this index has no upper limit and may also be sensitive to sample size, we also considered other standardized indices which are less sensitive to sample size. The NFI was 0.93, indicating an acceptable fit to the model. The CFI yielded a value of 0.94 and the IFI got a value of 0.94 . Finally, RMSEA value was 0.74 , indicating acceptable fit.

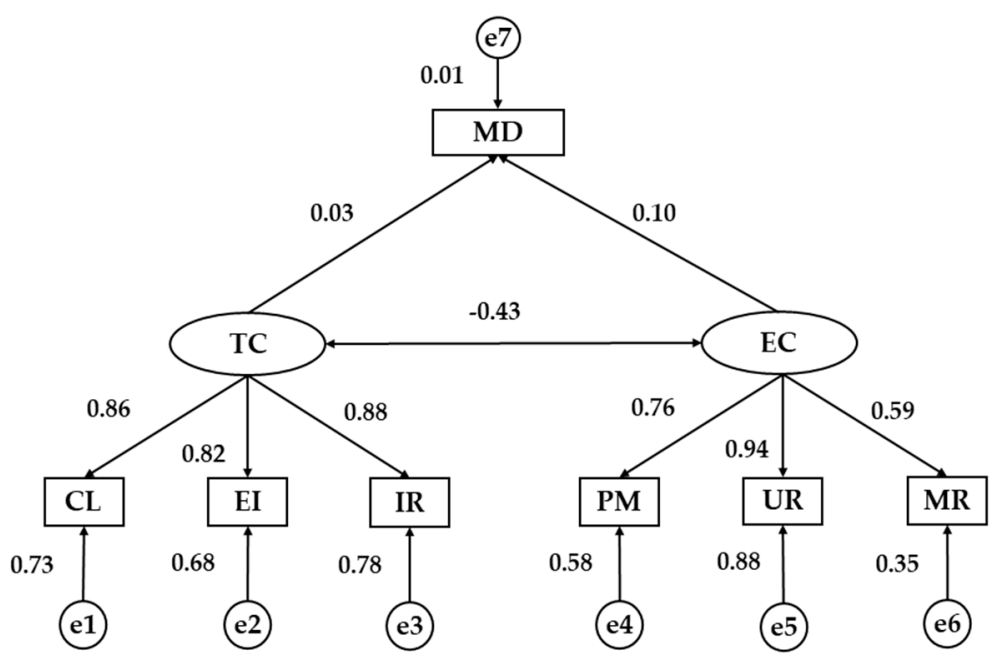

Figure 2. Structural Equation Model for Spanish students. TC, Task Climate; EC, Ego Climate; CL, Cooperative Learning; EI, Effort/Improvement; IR, Important Role; PM, Punishment for Mistakes; UR, Unequal Recognition; MR, Member Rivalry; MD, Mediterranean Diet. 


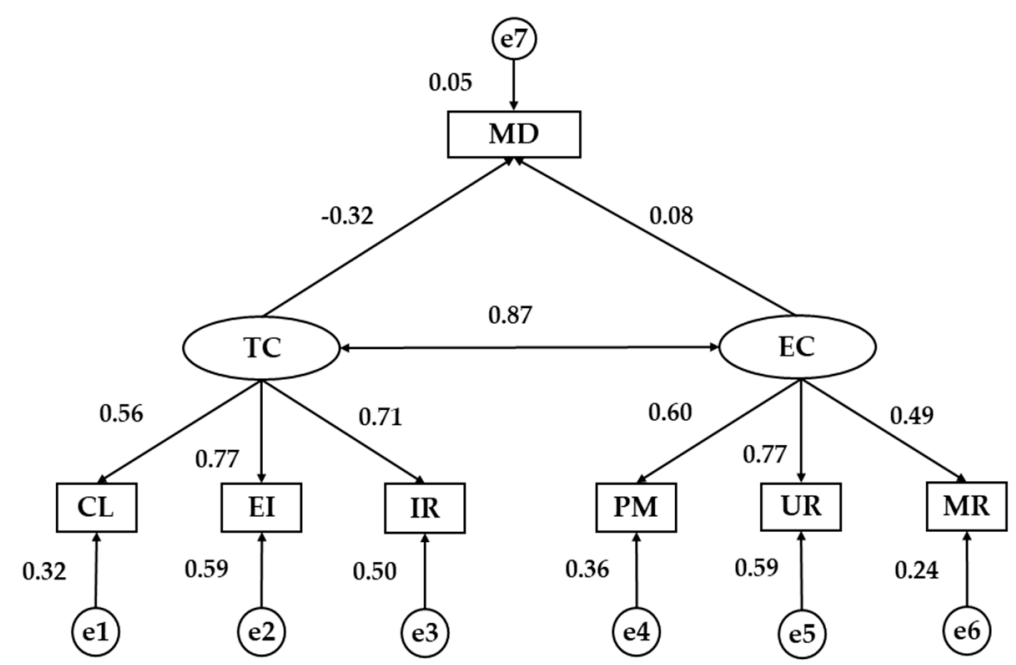

Figure 3. Structural Equation Model for Romanian students. TC, Task Climate; EC, Ego Climate; CL, Cooperative Learning; EI, Effort/Improvement; IR, Important Role; PM, Punishment for Mistakes; UR, Unequal Recognition; MR, Member Rivalry; MD, Mediterranean Diet.

Table 4 shows the standardized weights of university students from Spain and Romania. A significant negative relationship was found between the two dimensions of motivational climate for university students from both countries, being negative in Spaniards $(p<0.001, b=-0.429)$ and positive in Romanians $(p<0.001, b=0.872)$. In relation to the indicators and their association with the exogenous variables, the variable that showed the highest regression weight for the task-oriented climate in Spanish students was the important role $(p<0.001, b=0.884)$, while in the students from Romania it was the effort / improvement $(p<0.001, b=0.765)$. In the case of the ego-oriented climate, the indicator with the highest regression weight was unequal recognition for Spaniards and Romanians $(p<0.001, b=0.940 ; p<0.001 ; b=0.765)$.

Finally, the relationship between adherence to MD and motivational climate in sport is analysed (Table 4). A significant and positive relationship was obtained between the ego-oriented climate and the level of adherence to MD $(p<0.05, b=0.103)$ in young Spaniards, whereas this association was not significant for young Romanians. On the contrary, there was a statistically significant association between the task-oriented climate and the level of adherence to the MD, which was negative $(p<0.001, b=0.315)$. Nevertheless, this relationship was not statistically significant for Spanish university students. 
Table 4. Structural equation model: multi-group analysis according to country.

\begin{tabular}{|c|c|c|c|c|c|c|}
\hline \multirow{2}{*}{\multicolumn{3}{|c|}{$\begin{array}{c}\text { Relationship between } \\
\text { Variables }\end{array}$}} & \multicolumn{3}{|c|}{ R.W. } & \multirow{2}{*}{$\begin{array}{c}\text { S.R.W. } \\
\text { Estimations }\end{array}$} \\
\hline & & & Estimations & S.E. & C.R. & \\
\hline \multicolumn{7}{|c|}{ Weights and standardized regression weights of students from Spain } \\
\hline $\mathrm{CL}$ & $\leftarrow$ & $\mathrm{TC}$ & 1.000 & - & - & $0.856^{* * *}$ \\
\hline EI & $\leftarrow$ & $\mathrm{TC}$ & 0.848 & 0.042 & 19.996 & $0.823^{* * *}$ \\
\hline IR & $\leftarrow$ & $\mathrm{TC}$ & 1.057 & 0.049 & 21.424 & $0.884^{* * *}$ \\
\hline PM & $\leftarrow$ & $\mathrm{EC}$ & 1.000 & - & - & $0.759^{* * * *}$ \\
\hline UR & $\leftarrow$ & $\mathrm{EC}$ & 1.403 & 0.096 & 14.656 & $0.940^{* * *}$ \\
\hline MR & $\leftarrow$ & $\mathrm{EC}$ & 0.936 & 0.078 & 12.016 & $0.589^{* * *}$ \\
\hline MD & $\leftarrow$ & $\mathrm{TC}$ & 0.115 & 0.247 & 0.465 & 0.027 \\
\hline MD & $\leftarrow$ & $\mathrm{EC}$ & 0.451 & 0.252 & 2.786 & $0.103 *$ \\
\hline $\mathrm{EC}$ & $\Theta$ & $\mathrm{TC}$ & -0.159 & 0.024 & -6.723 & $-0.429^{* * *}$ \\
\hline \multicolumn{7}{|c|}{ Weights and standardized regression weights of students from Romania } \\
\hline CL & $\leftarrow$ & TC & 1.000 & - & - & $0.562 * * *$ \\
\hline EI & $\leftarrow$ & $\mathrm{TC}$ & 0.959 & 0.133 & 7.219 & $0.765^{* * *}$ \\
\hline IR & $\leftarrow$ & $\mathrm{TC}$ & 1.434 & 0.208 & 6.905 & $0.708^{* * *}$ \\
\hline PM & $\leftarrow$ & $\mathrm{EC}$ & 1.000 & - & - & $0.601^{* * * *}$ \\
\hline UR & $\leftarrow$ & $\mathrm{EC}$ & 1.479 & 0.188 & 7.883 & $0.765^{* * *}$ \\
\hline MR & $\leftarrow$ & EC & 1.085 & 0.191 & 5.669 & $0.494^{* * *}$ \\
\hline MD & $\leftarrow$ & $\mathrm{TC}$ & -0.977 & 1.337 & -3.731 & $-0.315^{* * *}$ \\
\hline MD & $\leftarrow$ & $\mathrm{EC}$ & 0.294 & 1.531 & 0.192 & 0.082 \\
\hline $\mathrm{EC}$ & $\leftrightarrow$ & $\mathrm{TC}$ & 0.167 & 0.032 & 5.286 & $0.872^{* * *}$ \\
\hline
\end{tabular}

R.W., Regression Weights; S.R.W., Standardized Regression Weights; S.E., Estimation of Error; C.R., Critical Ratio. TC, Task Climate; CL, Cooperative Learning; EI, Effort/Improvement; IR, Important Role; EC, Ego Climate; PM, Punishment for Mistakes; UR, Unequal Recognition; MR, Member Rivalry; MD, Mediterranean

Diet. ${ }^{*} p<0.05 ; * * * p<0.001 . \leftarrow$, Relationships between latent and observable indicators; $\boxminus$, Relationships between exogenous variables.

\section{Discussion}

Adherence to the MD has been studied in many countries [4,13,15-21]. Nevertheless, there are few studies comparing dietary habits and other aspects, such as motivational factors related to the practice of sport. The global score obtained for adherence to the MD was higher for Spanish students. This is due to Romania being a non-coastal country, located further north than Spain. This geographical location, which comes with a different climate and cultural customs, does not enable the cultivation of many of the typical foods of the Mediterranean basin (that constitute the MD) in Romania [6,9,12]. Nevertheless, there is a good amount of food exports in the countries of the European Union, which make these differences less important to the level of adherence to MD, as Baylis et al. [51] show.

It was found that the consumption of vegetables, fruits and juice is higher in Spanish students than in the Romanian students. This is due to the geographical and cultural characteristics of the Spanish region, as these products are frequently cultivated given the better climatological conditions, an easy access and a low price [12,52]. Furthermore, there is a large production of oranges in Spain. The importance of the intake of this fruit is established in society and juice is one of the most frequent methods of consumption. The benefits of consuming these foods are known since they are rich in vitamins and antioxidants, which encourage their consumption by the Spanish population $[52,53]$.

In addition, it was shown that Romanian students ate fruit or vegetables more than once a day with higher frequency than Spanish students. It has been observed that Spanish students follow a better diet and the consumption of these foods is globalized in general. Nevertheless, they did not achieve much higher scores in the consumption of fruit or vegetables. However, the higher consumption of vegetables and fruit among Romanian students may be justified by the participants who follow a healthy lifestyle. Moreover, the scores can be explained by the anthropometric characteristics of people from Eastern 
Europe and by the climatic conditions that require a higher food intake. Studies carried out around the world have highlighted the differences that exist between different countries $[9,12,54-56]$.

The geographical situation of Spain and its climate favour the consumption of food such as fish, milk or cereals more consumed among its students, whereas the diet model of Romanian students is more oriented towards the consumption of pasta or rice. On the other hand, it is worrisome that the consumption of sweets, processed foods or fast food is higher in Romanian students. This is because they have not adopted the Mediterranean diet within their dietary models and this promotes little or no consumption of these foods [13,52].

The motivational climate in sports practice has been studied in different contexts, mainly the field of Physical Education, competitive sports and healthy habits $[36,57,58]$. In the present study, higher scores have been observed in the task-oriented motivational climate of Spanish students, whereas Romanian students obtained higher scores in the ego-oriented motivational climate in all its dimensions. This could be explained by the type of sports that are practiced most frequently in these countries. Team sports such as football or basketball are more common in Spain, promoting factors that are more linked to the task climate, such as cooperation or teamwork [50,59]. On the contrary, there is a greater tendency for the practice of individual sports such as wrestling, sports gymnastics or weightlifting in Romania, making them stand out in a greater competitive context with the disappearance of the hedonistic factor $[40,60,61]$. Therefore, although both sports may link all kinds of motivations, those that involve greater social interaction and collaborative work will be related to more self-determined motivations. This idea, along with the cultural influences of each country, will justify these findings $[33,34,60]$.

In the relationship between the motivational climate and MD, those students who are oriented towards the task are those who have a lower adherence to MD. This can be explained by students that are intrinsically predisposed to the pleasure of physical activity and, thus, do not follow a diet of quality in order to improve their sport performance [41,62]. Nevertheless, the students who got higher scores for ego-oriented climate were those with a medium or high adherence to MD, may propitiated by the importance that has the feeding and the nutrition for the sports performance [6,63]. In addition, the scores in ego-oriented climate showed an increase in relation to medium adherence to MD in Romanian students, which is produced because they do not have low adherence in any case and the importance given to get good results in sport context [41]. On the contrary, the statistical differences are shown in task-oriented climate in Spanish university students. In this students an increase of the average scores of the task climate was linked to a low adherence to the MD. This can be justified by the intrinsic motivations of this group, who do not prioritize nutrition as much as they should, as they do not aim at a better performance like their competitors [64-68].

First, the limitations found in this study are determined by the cross-sectional design of this study, where data is collected at a specific time, not allowing to establish causal explanation of this variables. Another limitation is associated with the sample size, since data cannot be generalized to the general population of these countries. Only students between 18 and 24 years of age, enrolled in Physical Education and who have knowledge of nutrition have been analysed. It would also have been interesting to apply the PREDIMED questionnaire but this test that analyses the adherence to the MD in people older than 21 years was not appropriate for our participants (who were mostly less than that age). The variables selected represent another limitation since it would have been of interest to include the socio-economic level and the place of residence of the students in order to know their influence on the level of adherence to the MD. Lastly, with KIDMED being a self-report questionnaire, some comprehension errors could be found, although this is not impeding its application [41-48].

\section{Conclusions}

The present study show evidence for a higher adherence to MD among Spanish students, as indicated by a higher intake of fruit, vegetables, cereals and fish. On the contrary, Romanian students ate more pasta, rice and processed products such as sweets or fried foods. In relation to the 
motivational climate, it was observed that students from Spain obtained higher scores in task climate and students from Romania achieved higher scores in ego climate, due to the type of sports practiced. The relationship between these two variables suggested that the task-oriented motivational climate was related to a diet of poorer quality in young Spaniards, observing the opposite in students from Romania. Finally, the structural equation model revealed how the task-oriented climate exerted a negative influence on the adherence to DM in Romanian students, while the ego-oriented climate exerted a positive influence on the quality of the diet of Spanish students.

It has been shown that the existence of extrinsic motivations can be linked to better nutrition, both for health purposes and the achievement of better sports performance. Although the motivations of intrinsic type are linked to healthier habits associated with sport practice, these were not related to nutrition. While further research is necessary to substantiate the findings from this study, there are adequate indications to pursue development of intervention programs aimed at improving the quality of diet, especially among students in Romania. On the other hand, such programs are also of vital importance for Spanish students, in order to obtain a better quality of the diet in those intrinsically motivated.

Author Contributions: R.C.-C., G.B., F.Z.-O. and M.C.-S. conceived the hypothesis of this study. F.Z.-O., R.C.-C. and G.B. participated in data collection. R.C.-C., M.C.-S. and F.Z.-O. analysed the data. All authors contributed to data interpretation of the statistical analysis. F.Z.-O., M.C.-S. and G.B. wrote the paper with significant input from R.C.-C. All authors read and approved the final manuscript.

Funding: This research received no external funding.

Conflicts of Interest: The authors declare no conflict of interest.

\section{References}

1. Redondo, M.P.; De Mateos, B.; Carreno, L.; Marugan, J.M.; Fernández, M.; Camina, M.A. Dietary intake and adherence to the Mediterranean diet in a group of university students depending. Nutr. Hosp. 2016, 33, 1172-1178. [CrossRef]

2. Belogianni, K.; Ooms, A.; Ahmed, H.; Nikoletou, D.; Grant, R.; Makris, D.; Moir, H.J. Rationale and design of an Online educational program using game-based learning to improve nutrition and physical activity outcomes among university students in the United Kingdom. J. Am. Coll. Nutr. 2018, 1-8. [CrossRef] [PubMed]

3. Torstveit, M.K.; Johansen, B.T.; Haugland, S.H.; Stea, T.H. Participation in organized sports is associated with decreased likelihood of unhealthy lifestyle habits in adolescents. Scand. J. Med. Sci. Sports 2018, 28, 2384-2396. [CrossRef] [PubMed]

4. Zurita, F.; San Roman, S.; Chacon, R.; Castro, M.; Muros, J.J. Adherence to the Mediterranean Diet is associated with physical activity, self-concept and sociodemographic factors in university student. Nutrients 2018, 10, 966. [CrossRef] [PubMed]

5. Erwin, C.M.; McEvoy, C.T.; Moore, S.E.; Prior, L.; Lawton, J.; Kee, F.; Cupples, M.E.; Young, I.S.; Appleton, K.; McKinley, M.C.; et al. A qualitative analysis exploring preferred methods of peer support to encourage adherence to a Mediterranean diet in a Northern European population at high risk of cardiovascular disease. BMC Public Health 2017, 18, 213. [CrossRef] [PubMed]

6. Lotrean, L.M.; Stan, O.; Lencu, C.; Laza, V. Dietary patterns, physical activity, body mass index, weight-related behaviours and their interrelationship among Romanian university students-trends from 2003 to 2016. Nutr. Hosp. 2018, 35, 375-383. [CrossRef] [PubMed]

7. Esposito, K.; Maiorino, M.I.; Bellastella, G.; Panagiotakos, D.B.; Giugliano, D. Mediterranean diet for type 2 diabetes: Cardiometabolic benefits. Endocrine 2017, 56, 27-32. [CrossRef] [PubMed]

8. Godos, J.; Rapisarda, G.; Marventano, S.; Galvano, F.; Mistretta, A.; Grosso, G. Association between polyphenol intake and adherence to the Mediterranean diet in Sicily, southern Italy. NFS J. 2017, 8, 1-7. [CrossRef]

9. Yahia, N.; Achkar, A.; Abdallah, A.; Rizk, S. Eating habits and obesity among Lebanese university students. Nutr. J. 2008, 7, 32. [CrossRef] 
10. Ortiz-Moncada, R.; Norte, A.I.; Zaragoza, A.; Fernández, J.; Davo, M.C. Mediterranean diet patterns follow Spanish university students. Nutr. Hosp. 2012, 27, 1952-1959. [CrossRef]

11. García, S.; Herrera, N.; Rodríguez, C.; Nissensohn, M.; Román, B.; Serra-Majem, L. KIDMED test; prevalence of low adherence to the Mediterranean diet in children and young; a systematic review. Nutr. Hosp. 2015, 32, 2390-2399. [CrossRef]

12. Baldini, M.; Pasqui, F.; Bordoni, A.; Maranesi, M. Is the Mediterranean lifestyle still a reality? Evaluation of food consumption and energy expenditure in Italian and Spanish university students. Public Health Nutr. 2008, 12, 148-155. [CrossRef] [PubMed]

13. Noale, M.; Nardi, M.; Limongi, F.; Siviero, P.; Caregaro, L.; Crepaldi, G.; Maggi, S. Mediterranean Diet Foundation Study Group. Adolescents in southern regions of Italy adhere to the Mediterranean diet more than those in the northern regions. Nutr. Res. 2014, 34, 771-779. [CrossRef] [PubMed]

14. Muros, J.J.; Cofre-Bolados, C.; Arriscado, D.; Zurita-Ortega, F.; Knox, E. Mediterranean diet adherence is associated with lifestyle, physical fitness, and mental wellness among 10-y-olds in Chile. Nutrition 2017, 35 , 87-92. [CrossRef] [PubMed]

15. Sánchez-Villegas, A.; Ruiz-Canela, M.; Gea, A.; Lahortiga, F.; Martínez-González, M.A. The association between the Mediterranean lifestyle and depression. Clin. Psychol. Sci. 2016, 4, 1085-1093. [CrossRef]

16. Mosconi, L.; Walters, M.; Sterling, J.; Quinn, C.; McHugh, P.; Andrews, R.; Matthews, D.C.; Ganzer, C.; Osorio, R.S.; Isaacson, R.S.; et al. Lifestyle and vascular risk effects on MRI-based biomarkers of Alzheimer's disease: A cross-sectional study of middle-aged adults from the broader New York City area. BMJ Open 2018, 8, e019362. [CrossRef] [PubMed]

17. Santomauro, F.; Lorini, C.; Tanini, T.; Indiani, L.; Lastrucci, V.; Comodo, N.; Bonaccorsi, G. Adherence to Mediterranean diet in a simple of Tuscan adolescents. Nutrition 2014, 30, 1379-1383. [CrossRef]

18. Baydemir, C.; Ozgur, E.G.; Balci, S. Evaluation of adherence to Mediterranean diet in medical students at Kocaeli University, Turkey. J. Int. Med. Res. 2018, 46, 1585-1594. [CrossRef]

19. Kyriacou, A.; Evans, J.M.; Economides, N.; Kyriacou, A. Adherence to the Mediterranean diet by the Greek and Cypriot population: A systematic review. Eur. J. Public Health 2015, 25, 1012-1018. [CrossRef]

20. Roccaldo, R.; Censi, L.; D’Addezio, L.; Toti, E.; Martone, D.; D’Addesa, D.; Cernigliaro, A. ZOOM8 Study group. Adherence to the Mediterranean diet in Italian school children (the ZOOM8 study). Int. J. Food Sci. Nutr. 2014, 65, 621-628. [CrossRef]

21. Chacón-Cuberos, R.; Castro-Sánchez, M.; Muros-Molina, J.J.; Espejo-Garcés, T.; Zurita-Ortega, F.; Linares-Manrique, M. Adherence to Mediterranean diet in university students and its relationship with digital leisure habits. Nutr. Hosp. 2016, 33, 405-410. [CrossRef]

22. Padial-Ruz, R.; Viciana-Garófano, V.; Palomares, J. Adherence to the Mediterranean diet, physical activity and its relationship with the BMI, in university students of the grade of Primary, mention in Physical Education of Granada. Educ. Sport Health Phys. Act. 2018, 2, 30-49.

23. Stefan, L.; Cule, M.; Milinovic, I.; Juranko, D.; Sporis, G. The relationship between lifestyle factors and body compositionin young adults. Int. J. Environ. Res. Public Health 2017, 14, 893. [CrossRef]

24. Tognon, G.; Hebestreit, A.; Lanfer, A.; Moreno, L.A.; Pala, V.; Siani, A.; Tornaritis, M.; De Henauw, S.; Veidebaum, T.; Molnár, D.; et al. Mediterranean diet, overweight and body composition in children from eight European countries: Cross-sectional and prospective results from the IDEFICS study. Nutr. Metab. Cardiovasc. Dis. 2014, 24, 205-213. [CrossRef] [PubMed]

25. Abenavoli, L.; Greco, M.; Milic, N.; Accattato, F.; Foti, D.; Gulletta, E.; Luzza, F. Effect of Mediterranean diet and antioxidant formulation in non-alcoholic fatty liver disease: A randomized study. Nutrients 2017, 9, 870. [CrossRef] [PubMed]

26. Salas-Salvadó, J.; Bulló, M.; Babio, N.; Martínez-González, M.Á.; Ibarrola-Jurado, N.; Basora, J.; Estruch, R.; Covas, M.I.; Corella, D.; Arós, F.; et al. Erratum. Reduction in the Incidence of Type 2 Diabetes with the Mediterranean Diet: Results of the PREDIMED-Reus nutrition intervention randomized trial. Diabetes Care 2018, 34, 14-19. [CrossRef] [PubMed]

27. Trovato, F.M.; Catalano, D.; Martines, G.F.; Pace, P.; Trovato, G.M. Mediterranean diet and non-alcoholic fatty liver disease: The need of extended and comprehensive interventions. Clin. Nutr. 2015, 34, 86-88. [CrossRef]

28. O'neil, A.; Quirk, S.E.; Housden, S.; Brennan, S.L.; Williams, L.J.; Pasco, J.A.; Berk, M.; Jacka, F.N. Relationship between diet and mental health in children and adolescents: A systematic review. Am. J. Public Health 2014, 104, e31-e42. [CrossRef] 
29. Warburton, D.E.; Nicol, C.W.; Bredin, S.S. Health benefits of physical activity: The evidence. Can. Med. Assoc. J. 2006, 174, 801-809. [CrossRef]

30. Lewis, B.A.; Napolitano, M.A.; Buman, M.P.; Williams, D.M.; Nigg, C.R. Future directions in physical activity intervention research: Expanding our focus to sedentary behaviors, technology, and dissemination. J. Behav. Med. 2017, 40, 112-126. [CrossRef]

31. McMahon, E.M.; Corcoran, P.; O’Regan, G.; Keeley, H.; Cannon, M.; Carli, V.; Wasserman, C.; Hadlaczky, G.; Sarchiapone, M.; Apter, A.; et al. Physical activity in European adolescents and associations with anxiety, depression and well-being. Eur. Child Adol. Psychiatr. 2017, 26, 111-122. [CrossRef] [PubMed]

32. Krøll, L.S.; Hammarlund, C.S.; Westergaard, M.L.; Nielsen, T.; Sloth, L.B.; Jensen, R.H.; Gard, G. Level of physical activity, well-being, stress and self-rated health in persons with migraine and co-existing tension-type headache and neck pain. J. Headache Pain 2017, 18, 46. [CrossRef] [PubMed]

33. Roberts, G.C.; Treasure, D.C.; Balague, G. Achievement goals in sport: The development and validation of the Perception of Success Questionnaire. J Sports Sci. 1998, 16, 337-347. [CrossRef] [PubMed]

34. Ring, C.; Kavussanu, M. The impact of achievement goals on cheating in sport. Psychol. Sport Exerc. 2018, 35, 98-103. [CrossRef]

35. Lochbaum, M.; Kallinen, V.; Konttinen, N. Task and Ego Goal Orientations across the Youth Sports Experience. Stud. Sport. 2017, 11, 99-105. [CrossRef]

36. McLaren, C.D.; Newland, A.; Eys, M.; Newton, M. Peer-initiated motivational climate and group cohesion in youth sport. J. Appl. Sport Psychol. 2017, 29, 88-100. [CrossRef]

37. Chacón-Cuberos, R.; Muros-Molina, J.J.; Cachón, J.; Zagalaz, M.L.; Castro-Sánchez, M.; Zurita-Ortega, F. Physical activity, Mediterranean diet, maximal oxygen uptake and motivational climate towards sports in schoolchildren from the province of Granada: A structural equation model. Nutr. Hosp. 2018, 35, 774-781. [CrossRef]

38. Ryan, R.M.; Deci, E.L. Self-Determination Theory: Basic Psychological Needs in Motivation, Development, and Wellness; Guilford Publications: New York, NY, USA, 2017.

39. Hancox, J.E.; Quested, E.; Ntoumanis, N.; Thøgersen-Ntoumani, C. Putting self-determination theory into practice: Application of adaptive motivational principles in the exercise domain. Qual. Res. Sport Exerc. Health 2018, 10, 75-91. [CrossRef]

40. Hulleman, C.S.; Schrager, S.M.; Bodmann, S.M.; Harackiewicz, J.M. A meta-analytic review of achievement goal measures: Different labels for the same constructs or different constructs with similar labels? Psychol. Bull. 2010, 136, 422-449. [CrossRef]

41. Chacon, R.; Zurita, F.; Puertas, P.; Knox, E.; Cofre, C.; Viciana, V.; Muros, J.J. Relationship between healthy habits and perceived motivational climate in sport among university students: A structural equation model. Sustainability 2018, 10, 938. [CrossRef]

42. Moore, S.E.; McEvoy, C.T.; Prior, L.; Lawton, J.; Patterson, C.C.; Kee, F.; Cupples, M.; Young, I.S.; Appleton, K.; McKinley, M.C.; et al. Barriers to adopting a Mediterranean diet in Nothern European adults at high risk of developing cardiovascular disease. J. Hum. Nutr. Diet 2017, 31, 451-462. [CrossRef] [PubMed]

43. Chacón-Cuberos, R.; Zurita-Ortega, F.; Martínez-Martínez, A.; Olmedo-Moreno, E.; Castro-Sánchez, M. Adherence to the Mediterranean Diet Is Related to Healthy Habits, Learning Processes, and Academic Achievement in Adolescents: A Cross-Sectional Study. Nutrients 2018, 10, 1566. [CrossRef] [PubMed]

44. Erturan-Ilker, G.; Yu, C.; Alemdaroğlu, U.; Köklü, Y. Basic psychological needs and self-determined motivation in PE to predict health-related fitness level. J. Sport Health Res. 2018, 10, 91-100.

45. Dare, C.; Viebig, R.F.; Batista, N.S. Body composition and components of Mediterranean diet in Brazilian and European University Students. RBONE 2017, 11, 557-566.

46. Bottcher, M.R.; Marincic, P.Z.; Nahay, K.L.; Baerlocher, B.E.; Willis, A.W.; Park, J. Nutrition knowledge and Mediterranean diet adherence in the southeast United States: Validation of a field-based survey instrument. Appetite 2017, 111, 166-176. [CrossRef] [PubMed]

47. Merino-Marban, R.; Mayorga-Vega, D.; Fernandez-Rodríguez, E.; Estrada, F.; Viciana, J. Effect of a physical education-based stretching programme on sit-andreach score and its posterior reduction in elementary schoolchildren. Eur. Phys. Educ. Rev. 2015, 21, 83-92. [CrossRef]

48. Serra-Majem, L.; Ribas, L.; Ngo, J.; Ortega, R.M.; Garcia, A.; Pérez-Rodrigo, C.; Aranceta, J. Food, youth and the Mediterranean diet in Spain. Development of KIDMED, Mediterranean diet quality index in children and adolescents. Public Health Nutr. 2004, 7, 931-935. [CrossRef] 
49. Newton, M.; Duda, J.; Yin, Z. Examination of the psychometric properties of the Perceived Motivational in Sport Questionnaire-2 in a sample of female athletes. J. Sports Sci. 2000, 18, 275-290. [CrossRef]

50. González-Cutre, C.D.; Sicilia, A.; Moreno, J.A. The social-cognitive model of achievement motivation in physical education. Psicothema 2008, 20, 642-651.

51. Baylis, K.; Nogueira, L.; Pace, K. Food import refusals: Evidence from the European Union. Am. J. Agric. Econ. 2010, 93, 566-572. [CrossRef]

52. Celis-Morales, C.; Livingstone, K.M.; Affleck, A.; Navas-Carretero, S.; San Cristobal, R.; Martínez, J.A.; Marsaux, C.F.; Saris, W.H.M.; O’Donovan, C.B.; Forster, H.; et al. Correlates of overall and central obesity in adults from seven European countries: Findings from the Food4Me Study. Eur. J. Clin. Nutr. 2018, 72 , 207-219. [CrossRef] [PubMed]

53. Berry, E.M.; Arnoni, Y.; Aviram, M. The Middle Eastern and biblical origins of the Mediterranean diet. Public Health Nutr. 2011, 14, 2288-2295. [CrossRef] [PubMed]

54. Mantziki, K.; Renders, C.M.; Seidell, J.C. Water Consumption in European Children: Associations with Intake of Fruit Juices, Soft Drinks and Related Parenting Practices. Int. J. Environ. Res. Public Health 2017, 14, 583. [CrossRef] [PubMed]

55. Basu, S.; McKee, M.; Galea, G.; Stuckler, D. Relationship of soft drink consumption to global overweight, obesity, and diabetes: A cross-national analysis of 75 countries. Am. J. Public Health 2013, 103, 2071-2077. [CrossRef] [PubMed]

56. Bauman, A.; Bull, F.; Chey, T.; Craig, C.L.; Ainsworth, B.E.; Sallis, J.F.; Bowles, H.R.; Hagstromer, M.; Sjostrom, M.; Pratt, M.; et al. The international prevalence study on physical activity: Results from 20 countries. Int. J. Behav. Nutr. Phys. Act. 2009, 6, 1-11. [CrossRef] [PubMed]

57. Al-Yaaribi, A.; Kavussanu, M. Consequences of prosocial and antisocial behaviors in adolescent male soccer players: The moderating role of motivational climate. Psychol. Sport Exerc. 2018, 37, 91-99. [CrossRef]

58. Jaakkola, T.; Yli-Piipari, S.; Barkoukis, V.; Liukkonen, J. Relationships among perceived motivational climate, motivational regulations, enjoyment, and PA participation among Finnish physical education students. Int. J. Sport Exerc. Psychol. 2017, 15, 273-290. [CrossRef]

59. Harwood, C.G.; Keegan, R.J.; Smith, J.M.; Raine, A.S. A systematic review of the intrapersonal correlates of motivational climate perceptions in sport and physical activity. Psychol. Sport Exerc. 2015, 18, 9-25. [CrossRef]

60. Curran, T.; Hill, A.P.; Hall, H.K.; Jowett, G.E. Relationships between the coach-created motivational climate and athlete engagement in youth sport. J. Sport Exerc. Psychol. 2015, 37, 193-198. [CrossRef]

61. Gagea, A.; Marinescu, G.; Cordun, M.; Gagea, G.; Szabo, G.; Paunescu, M. Recreational sport culture in Romania and some European countries. Rev. Cercet. Interv. Soc. 2010, 31, 54-63.

62. Craig, C.L.; Marshall, A.L.; Sjostrom, M.; Bauman, A.E.; Booth, M.L.; Ainsworth, B.E.; Pratt, M.; Ekelund, U.; Yngve, A.; Sallis, J.F.; et al. International physical activity questionnaire: 12-country reliability and validity. Med. Sci. Sports Exerc. 2003, 35, 1381-1395. [CrossRef] [PubMed]

63. González-Valero, G.; Zurita-Ortega, F.; Puertas-Molero, P.; Chacón-Cuberos, R.; Garcés, T.E.; Sánchez, M.C. Education for health: Implementation of the program "Sportfruits" in schools of Granada. SPORT TK 2017, 6, 137-146. [CrossRef]

64. Heemsoth, T.; Retelsdorf, J. Student-student relations from the teacher versus student perspective: A multi-level confirmatory factor analysis. Meas. Phys. Educ. Exerc. Sci. 2018, 22, 48-60. [CrossRef]

65. Sánchez-Garcia, C.; López-Sánchez, G.F.; González-Carcelén, C.M.; Ibáñez-Ortega, E.J.; Díaz-Suárez, A. Physical fitness and body image of sports science students. Educ. Sport, Health, Phys. Act. 2018, 2, 92-104.

66. Ivashchenko, O.V.; Khudolii, O.M.; Yermakova, T.S.; Veremeenko, V.Y. Power abilities: The structure of development in girls of 12-14 years old. Pedagog. Psychol. Med.-Biol. Probl. Phys. Train. Sports 2018, 4, 195-202. [CrossRef]

67. Badau, A.; Badau, D.; Talaghir, L.G.; Rus, V. The impact of the needs and roles of nutrition counselling in sport. Hum. Sport. Med. 2018, 18, 88-96. [CrossRef]

68. Badicu, G. Physical Activity and Sleep Quality in Students of the Faculty of Physical Education and Sport of Braşov, Romania. Sustainability 2018, 10, 2410. [CrossRef]

(C) 2018 by the authors. Licensee MDPI, Basel, Switzerland. This article is an open access article distributed under the terms and conditions of the Creative Commons Attribution (CC BY) license (http:/ / creativecommons.org/licenses/by/4.0/). 